\title{
Improvement of Interlaminar Fracture Properties of Out of Autoclave Manufactured Carbon Fiber Reinforced Polymers Using Multi-Walled Carbon Nanotubes
}

\author{
Dimoka Polyxeni ${ }^{1}$, Kostagiannakopoulou Christina', Masouras Athanasios ${ }^{1}$, \\ Kostopoulos Vassilis ${ }^{1,2 *}$ \\ ${ }^{1}$ Department of Mechanical Engineering and Aeronautics, University of Patras, Patras, Greece \\ ${ }^{2}$ Institute of Chemical Engineering Sciences, Foundation for Research and Technology Hellas (ICE-HT/FORTH), Patras, Greece \\ Email: dimoka@mech.upatras.gr, kostagia@mech.upatras.gr, atmas@mech.upatras.gr, ^kostopoulos@mech.upatras.gr
}

How to cite this paper: Polyxeni, D. Christina, K., Athanasios, M. and Vassilis, K. (2019) Improvement of Interlaminar Fracture Properties of Out of Autoclave Manufactured Carbon Fiber Reinforced Polymers Using Multi-Walled Carbon Nanotubes. World Journal of Mechanics, 9, 147-162. https://doi.org/10.4236/wjm.2019.96010

Received: March 6, 2019

Accepted: May 26, 2019

Published: May 29, 2019

Copyright (c) 2019 by author(s) and Scientific Research Publishing Inc. This work is licensed under the Creative Commons Attribution International License (CC BY 4.0).

http://creativecommons.org/licenses/by/4.0/

\begin{abstract}
The present study aims to the development of Out of Autoclave (OoA) Carbon Fiber Reinforced Polymers (CFRPs) with increased interlaminar fracture toughness by using MWCNTs. The introduction of MWCNTs into the structure of CFRPs has been succeeded by using carbon nanotube-enriched sizing agent for the pretreatment of the fiber preform using an in-house developed methodology that can be easily scaled up. The positive effect of the proposed methodology on the interlaminar fracture toughness of the CFRP laminate was assessed by the increase of Mode I and Mode II interlaminar fracture toughness of the composites. Different wt $\%$ MWCNTs concentrations were used (namely $0.5 \%, 1 \%, 1.5 \%$ and $2.5 \%$ ). It was found that the nanomodified composites exhibit a significant increase of the interlaminar critical strain energy release rate $\mathrm{G}_{\text {IC }}$ and $\mathrm{G}_{\text {IIC }}$ of the order of $103 \%$ and $62 \%$ respectively, in the case of $1.5 \mathrm{wt} \%$ MWCNTs weight content. Scanning Electron Microscopy (SEM) of the fracture surfaces of CFRP samples revealed the contribution and the associated synergistic mechanisms of MWCNTs to the increase of the crack propagation resistance in the case of nano-modified CFRPs compared to the reference material.
\end{abstract}

\section{Keywords}

Multi-Walled Carbon Nanotubes (MWCNTs), Interlaminar Fracture Toughness, Multi-Scale Composites (CFRPs), Out of Autoclave (OoA) 


\section{Introduction}

Carbon Fiber Reinforced Polymers (CFRPs) are increasingly used as advanced structural materials in various fields of applications such as aerospace, automotive, sports, energy and military industries. This tendency is clearly driven by their high specific strength and stiffness as well as their corrosion resistance compared to the conventional metals. Carbon fibers (CFs) are the most ideal reinforcement candidates because of their attractive properties such as high strength and modulus, high electrical conductivity, high thermal conductivity and low density. On the other hand, epoxy resins are the mostly used thermosetting matrices in FRPs due to their good mechanical properties, excellent corrosion resistance, high thermal stability and high compatibility with carbon, glass and aramid fiber reinforcements. However, poor out-of-plane properties of composites are observed due to the absence of the through-thickness reinforcement in order to sustain transverse loads.

Therefore, the weak fiber-matrix interface and the brittle nature of epoxy matrix in composite laminates make them prompt to interlaminar failures, such as delamination. Hence, it is imperative to find an effective way to satisfy multifunctional requirements and through-thickness reinforcements without compromising the in-plane properties. To this direction, there have been a number of attempts where many researchers have successfully developed through the thickness reinforcement methods to improve the fracture toughness of FRPs by using different methods, such as z-pinning [1] [2] [3], 3-D weaving, stitching [4] [5] [6] knitting, interleaving and toughening the matrix using micro-phase particles including rubbery or thermoplastics polymers [7]. However, the major disadvantage of these approaches is the development of large resin rich areas within the composite structure and therefore the deterioration of their in-plane properties. In view of this, a new field of research has been evolved improving the thermosetting matrices with the incorporation of nano-sized fillers [8] [9] [10]. The nano-phase introduces additional energy dissipation mechanisms during failure and therefore contributes to the improvement of interlaminar fracture toughness of the composite. Thus, the multi-scale reinforcement approach has resulted in the enhancement of damage tolerance and multi-functionality of conventional composites.

Towards this direction, Multi Wall Carbon Nanotubes (MWCNTs) is highly potential filler due to the superior mechanical, electrical and thermal properties [11]. Furthermore, their high aspect ratio and specific surface area provides a solid background for increasing the fracture characteristics of a resin system, where MWCNTs have been homogeneously dispersed [12] [13] [14] [15]. In the case of nano-modified with MWCNTs epoxy matrix, which has been used for composite manufacturing, then a significant increase of the interlaminar fracture toughness has been reported by Kostopoulos et al. [12]. More precisely, in the case where $1 \%$ wt. MWCNTs has been homogeneously dispersed into the epoxy matrix the interlaminar fracture toughness $\mathrm{G}_{\mathrm{IC}}$ and $\mathrm{G}_{\mathrm{IIC}}$ of the composite was in- 
creased by $60 \%$ and $75 \%$ respectively. Gojny et al. has demonstrated an increase of fracture toughness of epoxy resin by $23 \%$, in the case $1 \mathrm{wt} \%$ amino-functionalized Double Wall CNTs has been homogeneously dispersed into the epoxy via three roll calander [16]. Davis et al. in [17] demonstrated that fluorine functionalized carbon nanotubes (f-CNTs) can be used in the midplane of a fiber reinforced epoxy composite laminate for increasing the Mode II interlaminar fracture toughness. The highest improvement of $27 \%$ in the average propagation $\mathrm{G}_{\text {IIC }}$ was observed with $0.5 \mathrm{wt} \% \mathrm{f}-\mathrm{CNTs}$.

Although the introduction of CNTs into composite laminates provide significant performance benefits dealing mainly with the interlaminar fracture characteristics and the resulted multi-functionality, many problems appear during the incorporation of CNTs into these materials, especially in the OoA manufacturing processes. A direct introduction of CNTs into epoxy matrix leads to increase of resin viscosity and an uneven nanofiller distribution into the manufactured component and/or filtering effects that block the resin close to the inlet gates. This difficulty makes almost impossible the direct introduction of CNTs during Out-of-Autoclave (OoA) processes such as resin infusion or resin transfer molding (RTM). Despite this problem, many attempts have been made to infuse nano-modified epoxy resin through the fiber preform for enhancing out-of-plane properties and are based on the significant decrease on the amount of CNTs into the resin and their functionalization to minimize agglomerates. More precisely, Zhou et al. [18] proposed the implementation of nanocomposites with $0.3 \mathrm{wt} \%$ CNTs by VARTM method and an improvement of $2 \%$ in flexural strength was reported. They found that MWCNT/epoxy suspension higher than $0.5 \mathrm{wt} \%$ could not penetrate the fabrics preform thus blocking the resin flow. Advani et al. [19] has studied the filtering effect of acid-oxidized MWCNTs on the fabric surface. Zhang et al. [20] reported the increase of $14 \%$ in tensile strength and $20 \%$ in modulus by infusing $1 \%$ wt. loading of functionalized MWCNTs into glass fabrics. Regarding the interlaminar fracture toughness, Tanoglu et al. [21] observed an enhancement of $8 \%$ in $\mathrm{G}_{\mathrm{IIC}}$ with $0.1 \%$ wt. amino functionalized CNTs composites whereas no significant improvement for $\mathrm{G}_{\mathrm{IC}}$ value was reported. K.T. Hsiao et al. [22] introduced CNFs into polyester matrix to manufacture a multiscale glass fiber reinforced composites by resin infusion process at various concentrations $(0.5,1,1.5 \mathrm{wt} \%)$. In the case of $1.5 \mathrm{wt} \%$ noticeable CNF filtration effect in the thickness direction was shown and the presence of micro-void formation in the specimens was observed.

Due to the existence of the resin filtering problem in VARTM processes, several studies have focused on the developing of a hybridization method for the introduction of CNT/CF into the final OoA product. The chemical vapor deposition (CVD) and chemically grafting methods to grow directly CNTs on the carbon fabric surface, are effective techniques for improving the interfacial bonding between fiber and matrix [23] [24] [25] [26]. The CVD approach, however, can cause a reduction in the strength of the carbon fibers due to the extreme conditions (high operational temperature over $700^{\circ} \mathrm{C}$ and large time of 
process stabilization) [27] and, therefore, compromise the tensile properties. Additionally, in light of this issue, many attempts have developed in order to well vertically align the carbon nanotubes on the carbon fiber surface [28]. Furthermore, this technique is difficult to implement on an industrial scale. As an alternate method, the spraying technique and electrophoretic deposition (EPD) of CNT fillers are industrial-coating and low-energy use techniques that offer the capacity of homogeneous coating of complex shapes with well adhered films of controlled thickness, thus improving out-of-plane properties such as interlaminar fracture toughness in case they are applied in each layer of the fiber preform. For the implementation of spraying technique, an airbrush system is used to spray the CNTs solution onto the fabric surface and then the solvent is removed remaining the CNTs-modified fabrics [29].

The objective of the present study is the introduction of the CNTs in to the fiber preform through an alternative methodology that includes its modification by the integration of MWCNTs in a form of CNTs-enriched sizing agent. A water-based solution with a given wt\% CNTs content was prepared and the carbon fiber woven reinforcement was passed through it at aiven rate. Then the fabric was dried, and the dry fabric used to prepare the fiber preform and the final preform was placed in to the mold. Then all preparation for steps for the application of OoA process was applied. During the nano-modification treatment of the woven fabric up to the application of infusion process all the steps have been performed in a closed hood equipped with the appropriate nano-filter under slight under-pressure. After the manufacturing of the CNT modified plates the effect on the influence of MWCNTs on the interlaminar fracture toughness of CFRPs was assessed. The goal of this work is to study the ability of MWCNTs to provide increased resistance against interlaminar cracking and delamination. In this work, five CFRP laminated plates were manufactured using liquid resin infusion (LRI) process, with different weight content of CNTs (0, 0.5, 1, 1.5 and 2.5 wt\%). Mode I and Mode II tests were carried out and the fracture energy as a function of the MWCNT content was measured. Finally, energy dissipation mechanisms, where the nano fillers contribute, were demonstrated by detail observation of fracture surfaces using scanning electron microscope (SEM).

\section{Manufacturing Processes}

\subsection{Materials}

The matrix material used in this study was a three-part epoxy system provided by Resoltech Advanced Technology Resin (France). This resin system consists of an epoxy resin (Resolcoat 1400), an anhydride hardener (Resolcoat 1407) and an imidazole accelerator (AC140), which are typically mixed in ratios of 100:90:0.5 by weight, as recommended by the manufacturer [30]. The hardener and the accelerator were premixed, and the epoxy resin was preheated at $40^{\circ} \mathrm{C}$ before adding the cold hardener. The resulting epoxy system has a low viscosity, good mechanical adhesion and is very versatile for fabricating composite parts using re- 
sin transfer molding technique.

The main reinforcement phase was a twill weave carbon fabric with a density per unit area of $194 \mathrm{~g} / \mathrm{m}^{2}$, having $3 \mathrm{~K}$ filaments in the fiber bundle and a dry ply thickness of approximately $0.35 \mathrm{~mm}$. The carbon fabric reinforcement (having fiber type TR30S) was supplied by Fibermax Composites (Greece). The Pyrofil TR30S fiber type is a high strength and high modulus aerospace fiber with a reported tensile strength up to $4410 \mathrm{MPa}$, an elastic modulus close to $235 \mathrm{GPa}$ and density of $1.79 \mathrm{~g} / \mathrm{cm}^{3}$ [31].

Regarding the nano-phase, a liquid CNT-enriched sizing agent (SIZICYL XC $\mathrm{R} 2 \mathrm{G}$ ) was purchased from Nanocyl SA, Belgium. It is a sizing agent modified with $6.2 \%$ maximum solid content of MWCNTs (NC7000, Nanocyl) to size fabrics before impregnation by the resin matrix [32]. It has excellent compatibility with glass and carbon fibers to improve mechanical properties of a composite structure, without affecting the viscosity of the resin used to impregnate the fiber.

\subsection{Preparation of MWCNTs Suspension}

The MWCNT-enriched sizing agent solution was prepared by mixing an amount of sizing agent into a suitable quantity of distilled water, obtaining a water solution with certain content of CNTs. Different solutions with different CNT content was used for the pretreatment of the carbon fabric to conclude to different CNTs wt $\%$ content. Then, ultrasonic processing with a tip sonication device (Bandelin) was employed to homogeneous disperse the MWCNTs in the suspension for $3 \mathrm{~h}$, operated at an output power of $60 \mathrm{~W}$. To avoid temperature increases in the bulk solution during ultrasonication, the mixing pot was placed into a temperature control bath with continuous feed of fresh water. The quality control of the mixture was performed using a grindometer to confirm the absence of agglomerates. Finally, prior to pretreatment of carbon fabric reinforcement, the prepared water-based solution was degassed in a vacuum chamber for about 5 $\min$.

\subsection{Nano-Reinforced CFRP Laminates}

Composite plates with various CNTs concentrations (0, 0.5, 1, 1.5 and $2.5 \mathrm{wt} \%)$ were manufactured using an in-house developed process. Carbon fiber reinforced composite laminated plates (CFRPs) of $200 \times 300 \mathrm{~mm}^{2}$ were produced by Vacuum Assisted Resin Infusion process (VARI).

The prepared water based MWCNTs suspension, described earlier was used for the nano-modification of dry carbon fabrics in a closed hood equipped with the appropriate nano-filters under slight under-pressure. The fabric reinforcement was passed through the solution at a given rate and slightly compressed at the output of the solution bath. Then, the nano-modified wet fabrics were left to dry using a thermal plate. To calculate the final amount of MWCNTs deposited/infiltrated in the carbon fabrics, the mass of a given carbon fabric surface was measured before and after deposition. 
Each laminate was composed of sixteen carbon fabric layers and a $13 \mu \mathrm{m}$ thick PTFE (polytetrafluoroethylene) film of $70 \mathrm{~mm}$ wide and $250 \mathrm{~mm}$ long was placed in the middle plane (between $8^{\text {th }}$ and $9^{\text {th }}$ ply) of each plate to generate the starter crack, which is required to perform the interlaminar fracture tests. In the case of nano-doped laminates, four nano-modified CF layers for each filler content were placed in the middle of the laminates. Then, the carbon fabrics of each laminate were stacked on a mold, covered by a highly permeable medium and sealed with vacuum bag. The epoxy resin was infused through the fabrics and the laminates were cured in a conventional oven at $80^{\circ} \mathrm{C}$ for $4 \mathrm{~h}$ followed by post-cure profile at $140^{\circ} \mathrm{C}$ for $4 \mathrm{~h}$ according to manufacturer instructions. The step by step preparation of doped CFRP laminates is schematically depicted in Figure 1. Reference and unmodified CFRP plates, were also manufactured. The thickness and the fiber volume fraction of all produced plates were measured around $3.1 \mathrm{~mm}$ and $58 \%$ respectively, while the exact figures are shown in Table 1. Ultrasonic inspection was carried out utilizing the C-scan equipment (pulse-eco technique with $5 \mathrm{kHz}$ transducer) and the results showed very good and fully acceptable quality of the manufactured plates, without major defects (thickness variations, inhomogeneities and porosity).

\subsection{Mode I and Mode II Fracture Tests}

The resistance to interlaminar crack propagation of the produced laminates was defined by performing two types of fracture toughness experiments both for reference and MWCNT-modified specimens to quantify the interlaminar toughening effect resulted by the nano-modification of woven fabric with MWCNTs. A hydraulic universal testing machine (Instron, 8872) equipped with a $25 \mathrm{kN}$ loadcell was used for Mode I and Mode II tests. Five samples were tested for each type of material and for each type of experiment. The energy release rate under Mode I $\left(\mathrm{G}_{\mathrm{IC}}\right)$ was determined by using the double cantilever beam (DCB) method and was carried out according to ASTM standard D5528 [33]. DCB specimens were cut with the length of $250 \mathrm{~mm}$, width of $25 \mathrm{~mm}$ and an initial crack length of $25 \mathrm{~mm}$. Crack propagation was visually observed from the specimens marked side surface using a CCD camera equipped with a magnification lens $(\times 10)$. The crosshead speed used was $5 \mathrm{~mm} / \mathrm{min}$.

Table 1. Thickness and fiber volume fraction of produced laminates.

\begin{tabular}{cccc}
\hline Laminate & $\begin{array}{c}\text { MWCNTs content } \\
(\mathrm{wt} \%)\end{array}$ & $\begin{array}{c}\text { Thickness } \\
(\mathrm{mm})\end{array}$ & $\begin{array}{c}\text { Fiber volume } \\
\text { fraction } \mathrm{V}_{\mathrm{f}}(\%)\end{array}$ \\
\hline Plate 1-Ref. & 0 & $3.06 \pm 0.02$ & 58 \\
Plate 2-P05 & 0.5 & $3.13 \pm 0.03$ & 57 \\
Plate 3-P10 & 1 & $3.11 \pm 0.06$ & 58 \\
Plate 4-P15 & 1.5 & $3.07 \pm 0.03$ & 58 \\
Plate 5-P25 & 2.5 & $3.2 \pm 0.02$ & 55 \\
\hline
\end{tabular}




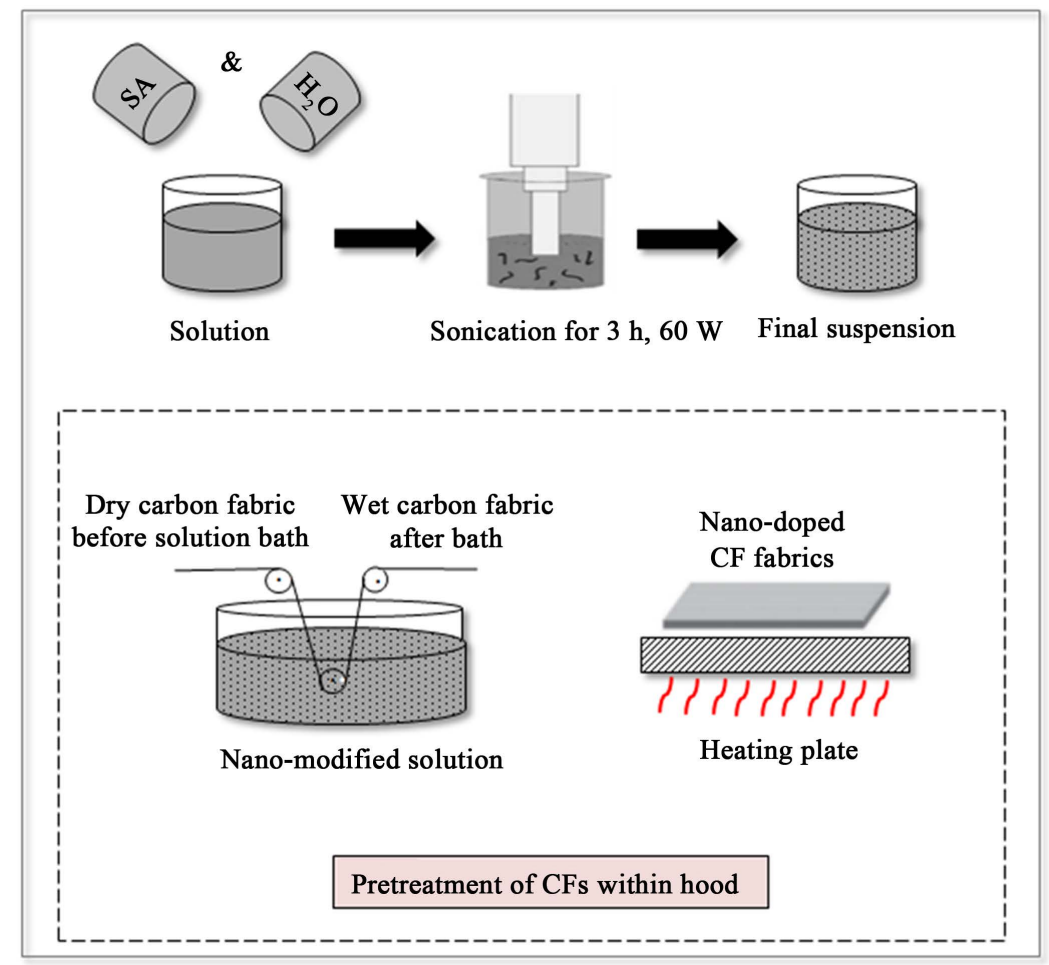

(a)

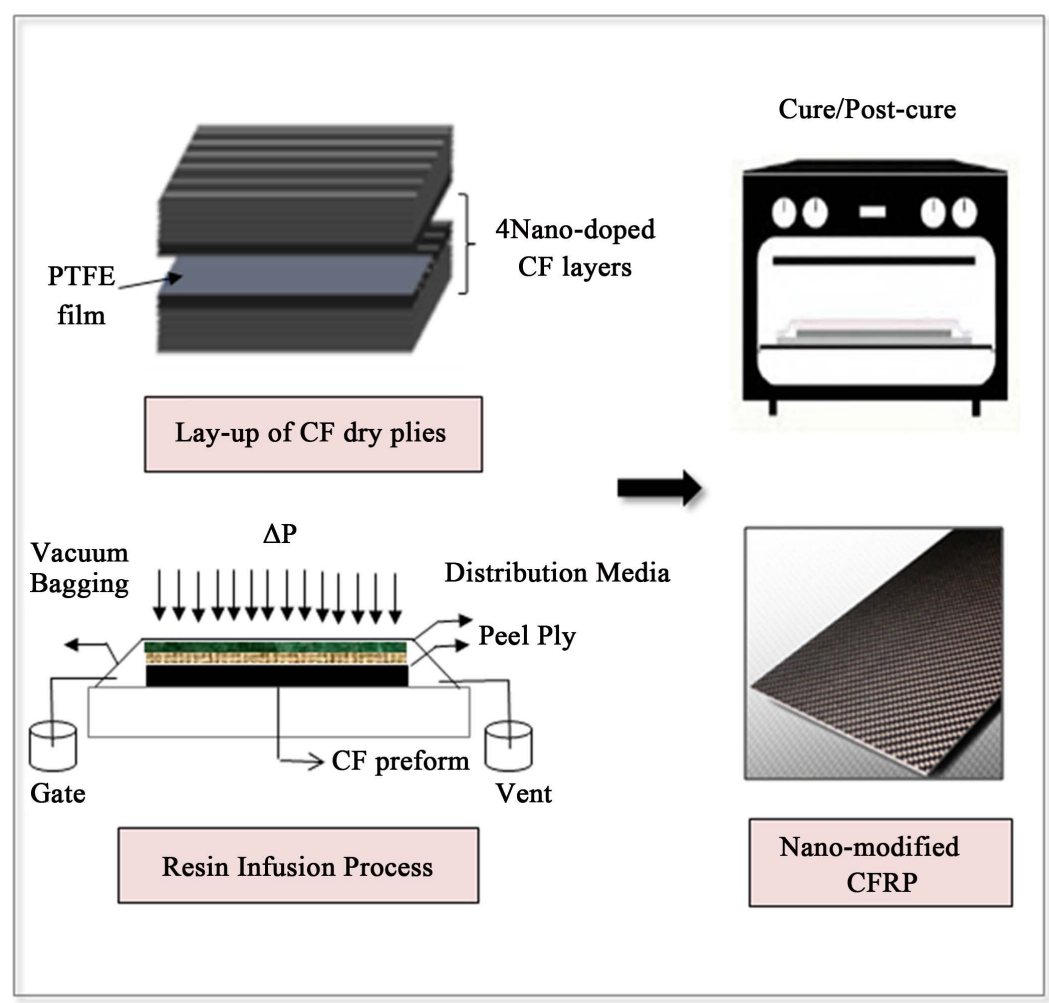

(b)

Figure 1. Illustration ofstep by step preparation process of nano-modified CFRP laminates. (a) The pretreatment process of dry carbon fiber to produce nano-modified reinforcement; and (b) The manufacturing production of CFRP laminates using infusion process. 
The Mode II interlaminar fracture toughness $\left(\mathrm{G}_{\mathrm{IIC}}\right)$ was measured by using the three-point end notched-flexure (3ENF) method in accordance to ASTM D7905 [34]. The test specimens were $120 \mathrm{~mm}$ long with the nominal specimen span length (2 L) of $100 \mathrm{~mm}$ and a nominal half-span length (L) of $50 \mathrm{~mm}$. (The nominal thickness of the samples used in mode II tests is slightly smaller to the one suggested by the standard i.e. $3.1 \mathrm{~mm}$ instead of $3.38 \mathrm{~mm}$ ). The crosshead speed was kept at $1 \mathrm{~mm} / \mathrm{min}$. Finally, the fracture surfaces of tested specimens were examined using a FEI InspectTM F50 Scanning Electron Microscopy (SEM).

\section{Results and Discussion}

\subsection{Mode I DCB Tests}

Typical load-displacement curves of DCB specimens for the reference and nano-doped laminates are displayed in Figure 2(a). Both the reference and nano-doped laminates show a linear load-displacement relationship up to the point of the crack initiation, after which they demonstrate distinct crack growth mechanism. The initiation value $\mathrm{G}_{\mathrm{IC} \text {,initiation }}$ is defined from deviation of linearity and the propagation value $\mathrm{G}_{\mathrm{IC} \text {,propagation }}$ obtained from the average of five samples for each material at the plateau region and reported in Table 2. Finally, it is obvious that the MWCNTs modified CFRPs achieve higher maximum loads, which corresponds to higher critical loads during the crack propagation than the reference material.

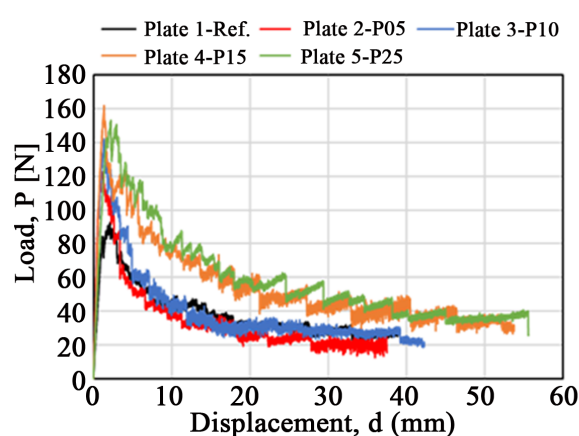

(a)

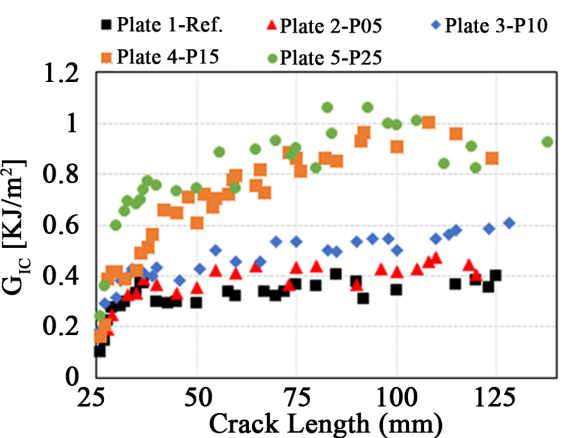

(b)

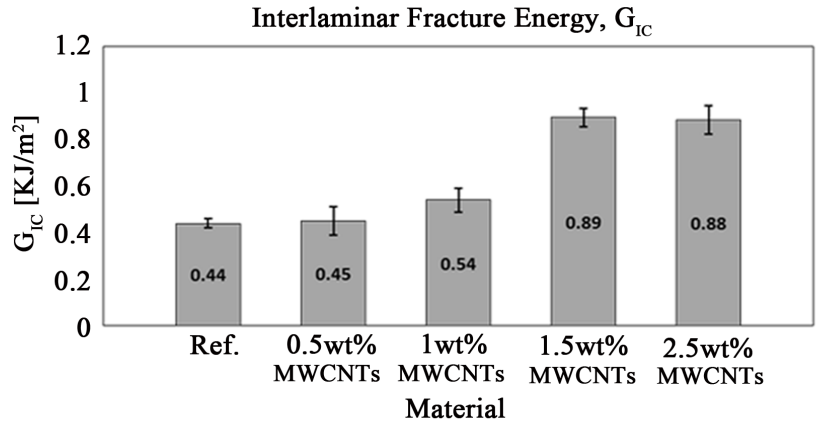

(c)

Figure 2. Mode I interlaminar fracture energy (a) load-displacement curves; (b) R curves; and (c) Strain energy release rate $\mathrm{G}_{\mathrm{IC}}$ for carbon/epoxy composites with different CNTs concentrations. 
Table 2. Summary of $\mathrm{G}_{\mathrm{IC}}$ fracture toughness values for all tested specimens.

\begin{tabular}{cccccc}
\hline & & \multicolumn{3}{c}{ Interlaminar fracture toughness $\mathrm{G}_{\mathrm{IC}}\left(\mathrm{KJ} / \mathrm{m}^{2}\right)$} \\
\cline { 3 - 6 } Laminate & $\begin{array}{c}\text { MWCNTs content } \\
(\text { wt\% })\end{array}$ & \multicolumn{2}{c}{ Initiation } & \multicolumn{2}{c}{ Propagation } \\
\cline { 3 - 6 } & & AVG & STDEV & AVG & STDEV \\
\hline Plate 1-Ref. & 0 & 0.16 & 0.03 & 0.44 & 0.02 \\
Plate 2-P05 & 0.5 & 0.24 & 0.09 & 0.45 & 0.06 \\
Plate 3-P10 & 1 & 0.23 & 0.04 & 0.54 & 0.05 \\
Plate 4-P15 & 1.5 & 0.22 & 0.1 & 0.89 & 0.04 \\
Plate 5-P25 & 2.5 & 0.24 & 0.05 & 0.85 & 0.13 \\
\hline
\end{tabular}

Mode I fracture toughness for reference and nano-modified CFRP specimens is characterized by a crack resistance ( $\mathrm{R}$ curves) behavior that includes an initiation value, a region of increasing toughness (resistance) as the crack extends until a steady-state value is reached, which corresponds to a self-similar crack advance. The R-curves represent the general trend of fracture toughness as a function of crack growth. As it is evident in Figure 2(b), there is an initial part where crack growth resistance increases versus crack length and this part followed by a region of almost constant crack resistance value, the plateau region, (typical $\mathrm{R}$ curve behavior). It is clearly seen that $\mathrm{G}_{\text {IC }}$ values of nano-doped specimens with the addition of $1.5 \mathrm{wt} \%$ MWCNTs rise sharply compared to the other laminates with lower MWCNTs content. This proves the positive effect of MWCNTs fillers at highest concentration in the interlaminar fracture energy.

Mode I fracture energy for each prepared CFRP either reference or nanomodified is summarized in Figure 2(c). It is clearly seen that the addition of 0.5 wt $\%$ and $1 \mathrm{wt} \%$ MWCNTs did not showed significant improvement in $\mathrm{G}_{\mathrm{IC}}$ values, compared to reference material. On the other hand, it is evident that the addition of $1.5 \mathrm{wt} \%$ MWCNTs into the structure of woven fabric reinforcement caused higher improvement of $\mathrm{G}_{\mathrm{IC}}$ value as it is compared against with the reference material. More precisely, the integration of $1.5 \mathrm{wt} \%$ MWCNTs achieved the highest increase of $103 \%$ in $\mathrm{G}_{\mathrm{IC}}$. Finally, it was concluded that further increase of MWCNTs content did not provide further enhancement of $\mathrm{G}_{\mathrm{IC}}$ toughness due to agglomerates formation. Furthermore, the initiation value for all the nano-modified CFRPs remains almost the same, although higher that the reference one.

\subsection{Mode II ENF Tests}

Typical load-deflection curves of the ENF tests for reference and nano-doped laminates are given in Figure 3(a). All specimens for each type of material showed a similar behavior. More precisely, the applied load increases linearly until the onset of the crack propagation, which is indicated by the deviation from the elastic region. The load-displacement behavior of each material is different. As a first conclusion the slope of load displacement curve of the reference 


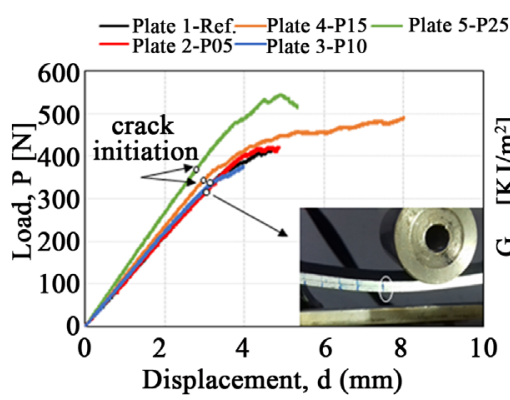

(a)

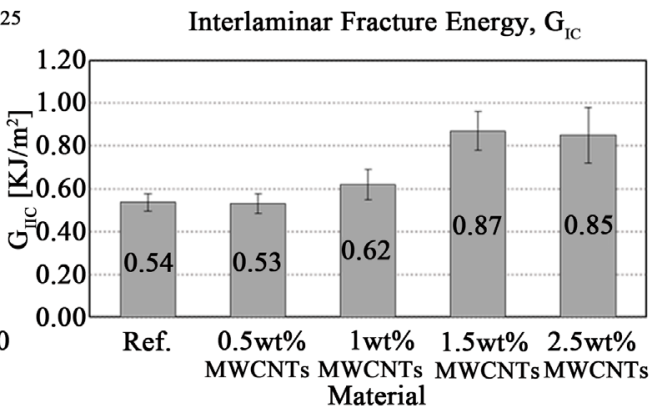

(b)

Figure 3. Mode II Interlaminar Fracture Toughness (a) load-displacement curves and (b) comparison of average $\mathrm{G}_{\text {IIC }}$ for carbon/epoxy composites with different CNTs concentrations.

material almost coincides with the slop of the low content MWCNTs modified composites ( 0.5 and $1.0 \mathrm{wt} \%$ ). For higher MWCNTs content this slope is slightly increased, and this is more significant in the case of $2.5 \mathrm{wt} \%$ MWCNTs content. Furthermore, for the reference plate the applied load increases linearly until the onset of the pre-crack propagation where the load drops. On the other hand, in the case of MWCNTs modified CFRPs with higher concentrations (1.5 and 2.5 $\mathrm{wt} \%$ MWCNTs) the linear load-displacement relationship is followed by a distinguishable deviation from linearity and much later the load drop appears. The average values and standard deviations for all manufactured CFRP plates are presented in Figure 3(b). As we can see, the addition of $0.5 \mathrm{wt} \%$ MWCNTs did not lead to any enhancement of $\mathrm{G}_{\text {IIC }}$ compared to the reference material, while marginally enhancement (16\%) achieved with the addition of $1 \mathrm{wt} \%$. On the other hand, the introduction of higher amount of MWCNTs in to the woven fabric reinforcement caused a significant improvement in Mode II fracture toughness. More precisely, the increase in $\mathrm{G}_{\text {IIC }}$ achieved in the case of $1.5 \mathrm{wt} \%$ MWCNTs nano-modified composite is of $62 \%$ compared to reference laminate without further improvement succeeded in the case of $2.5 \mathrm{wt} \%$. This is in complete agreement with the results presented earlier for $\mathrm{G}_{\mathrm{IC}}$ and the explanation is again the formation of CNT agglomerates that violate structural integrity does not further promote interlaminar fracture toughness.

Table 3 summarizes the increase achieved in Mode I and Mode II interlaminar fracture toughness of the composite laminates compared against the reference material, with the incorporation of various amounts of MWCNTs into the carbon fabric reinforcement. Taking into consideration the results presented above, we can conclude that the introduction of $1.5 \mathrm{wt} \%$ MWCNTs into the woven fabric reinforcement significantly increase the fracture toughness of resulted CFRPs compared against the reference one. This increase is associated to additional toughening/energy dissipation mechanisms that have been incorporated into the material structure during the interlaminar crack propagation. The effect of the energy absorption mechanisms introduced by MWCNTs is mainly demonstrated at the higher amount of MWCNTs used for the nano-modification 
Table 3. Summary of fracture toughness improvement compared to reference material.

\begin{tabular}{cccc}
\hline Laminate & $\begin{array}{c}\text { MWCNTs content } \\
(\mathbf{w t} \%)\end{array}$ & $\begin{array}{c}\mathrm{G}_{\mathrm{IC}} \text { increase } \\
\text { compared to Reference }\end{array}$ & $\begin{array}{c}\mathrm{G}_{\mathrm{IIC}} \text { increase } \\
\text { compared to Reference }\end{array}$ \\
\hline Plate 1-Ref. & 0 & - & - \\
Plate 2-P05 & 0.5 & $3 \%$ & $0 \%$ \\
Plate 3-P10 & 1 & $23 \%$ & $16 \%$ \\
Plate 4-P15 & 1.5 & $103 \%$ & $62 \%$ \\
Plate 5-P25 & 2.5 & $101 \%$ & $58 \%$ \\
\hline
\end{tabular}

of the woven fabric reinforcement. This effect is marginal in the case of lower MWCNTs content, especially under mode II remote loading.

\subsection{Fractographic Analysis}

The morphology and microstructure of fracture surfaces of the tested composites were also investigated by scanning electron microscopy analysis (SEM) after Mode I and Mode II tests in regions closed to the nano-modified carbon fibers. This SEM examination was used in order to confirm the additional toughening mechanisms that have been introduced by MWCNTs that were responsible for the improvement in both $\mathrm{G}_{\mathrm{IC}}$ and $\mathrm{G}_{\mathrm{IIC}}$.

Figure 4 presents the failure mechanisms that were observed in the case of MWCNTs contents $(0,0.5,1,1.5$ and $2.5 \mathrm{wt} \%)$. The reference CFRP composite has a very smooth fracture surface, as observed in Figure 4(a) that indicates the brittle behavior of epoxy resin. Furthermore, depicts the crack propagation along the fiber-matrix interface revealing a weak interfacial adhesion between fabric and matrix. Figure 4(b) presents the fracture surface of composite containing $0.5 \mathrm{wt} \%$ MWCNTs. A smooth fracture surface is still exhibited, as observed in the reference material. Additionally, a small presence of carbon nanotubes is revealed in the fiber-matrix interface. Towards this direction, in the case of $0.5 \mathrm{wt} \%$ MWCNTs the interlaminar fracture energy both for $\mathrm{G}_{\mathrm{IC}}$ and $\mathrm{G}_{\mathrm{IIC}}$ is not increased due to the absence of significant additional energy absorption mechanisms.

Figure 4(c) and Figure 4(d) present the main failure mechanisms that were observed during fracture in the cases of the increasing contents (1 and $1.5 \mathrm{wt} \%$ MWCNTs), respectively. By the micrographs captured at different magnifications, carbon nanotubes were distributed uniformly into the material's structure and the absence of MWCNT agglomerates was verified. Also, along the fracture surfaces it was observed that carbon nanotubes were pulled-out operating as crack-bridging elements. The red framed areas and the red arrows at these figures indicate the pull-out toughening mechanisms that were activated with the introduction of MWCNTs. This toughening mechanism indicates that the carbon nanotubes operate as crack-bridging elements and resists to crack opening and interlaminar crack propagation. In parallel, due to the presence of MWCNTs that acts as micro-pins along the crack front, in some cases these micro-pins 


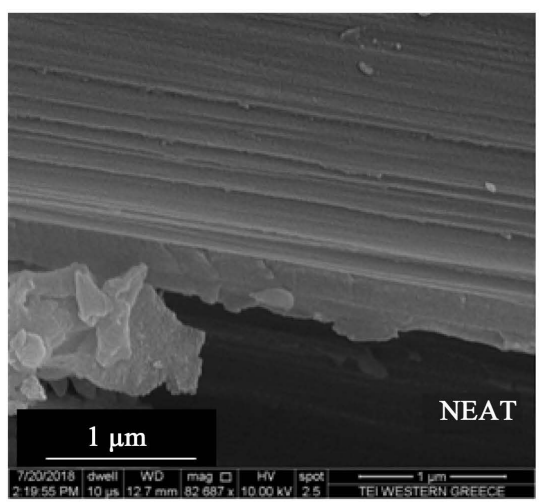

(a)

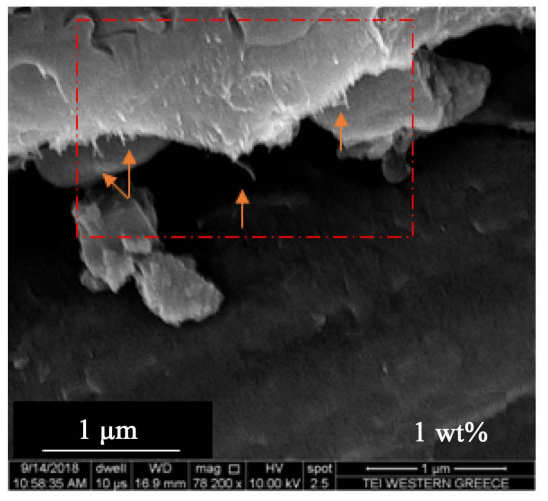

(c)

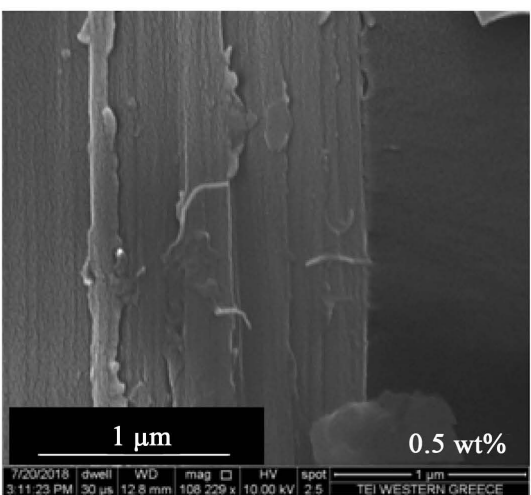

(b)

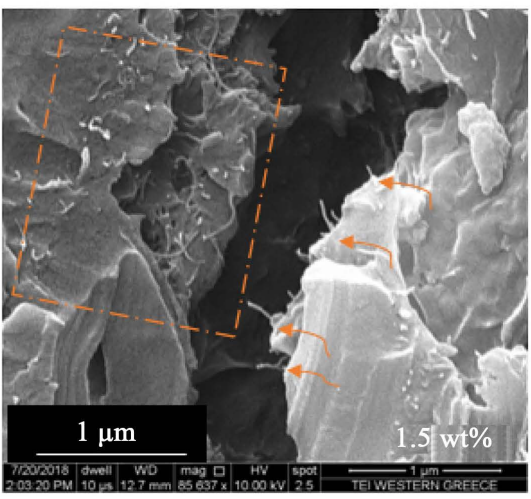

(d)

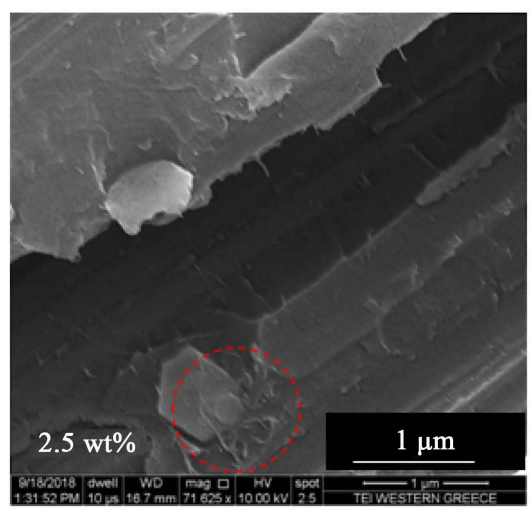

(e)

Figure 4. SEM images of fracture surface of reference material (a); nano-reinforced composites with 0.5 (b); 1 (c); 1.5 (d) and 2.5 (e) wt\% MWCNTs after Mode I and Mode II tests at different magnifications.

promote crack bifurcation whenever the micro-pins cannot be removed or broken. All these additional energy absorption mechanisms contribute at macroscale, to the increase of composite interlaminar fracture energy at the CNT concentration (1.5 wt\% MWCNTs). Finally, the slight degradation of fracture properties observed, in the case of nano-modified CFRP samples with the highest concentration, is associated to the presence of a small size of agglomerates, circled in Figure $4(\mathrm{e})$. This is supposed that this observation may be in whole structure. 


\section{Conclusion}

In this work, multi-walled carbon nanotubes (MWCNTs) fillers were utilized for the development of multi-scale laminated composite for Out-of-Autoclave (OoA) manufacturing processes. Towards this direction, a nano-modified solution enriched with multi-walled carbon nanotubes was prepared while the development of nano-modified carbon fiber/epoxy laminates was produced using vacuum assisted infusion process. The objective of this study is the investigation of interlaminar fracture toughness of nano-modified CFRPs at different CNTs contents $(0.5,1,1.5 \& 2.5 \mathrm{wt} \%)$. The fracture toughness and the fractographic analysis of these composites were performed to assess the contribution of carbon nanotubes to the interlaminar fracture toughness of the resulted composites. The fracture toughness of nano-modified laminates showed no significant difference with respect to the reference composites in the case of low wt\% MWCNTs content. Higher amount of MWCNTs at the level of $1.5 \mathrm{wt} \%$ increase significantly both mode I and mode II interlaminar fracture toughness of the composite laminate compared to the reference material and an increase of $103 \%$ and $62 \%$ respectively was achieved. Higher amount of MWCNTs lead to massive agglomerations and violate the positive effect of the nano-phase in energy absorption. The present MWCNTs activate at microscale energy absorption mechanisms such as bridging, and crack bifurcation thus resulting in an increase of the interlaminar fracture toughness at macroscale both under mode I and mode II remote loading.

\section{Acknowledgements}

The authors gratefully acknowledge the support of Dr. Kalarakis Alexandros for his assistance to SEM characterization of the fracture surfaces of the composites.

\section{Conflicts of Interest}

The authors declare no conflicts of interest regarding the publication of this paper.

\section{References}

[1] Mouritz, A.P. (2007) Review of Z-Pinned Composite Laminates. Composites Part A: Applied Science and Manufacturing, 38, 2383-2397. https://doi.org/10.1016/j.compositesa.2007.08.016

[2] Cartié, D.D.R., Troulis, M. and Partridge, I.K. (2006) Delamination of Z-Pinned Carbon Fibre Reinforced Laminates. Composites Science and Technology, 66, 855-861. https://doi.org/10.1016/j.compscitech.2004.12.018

[3] M’membe, B., Gannon, S., Yasaee, M., Hallett, S.R. and Partridge, I.K. (2016) Mode II Delamination Resistance of Composites Reinforced with Inclined Z-Pins. Materials \& Design, 94, 565-572. https://doi.org/10.1016/j.matdes.2016.01.051

[4] Dransfield, K., Baillie, C. and Mai, Y.W. (1994) Improving the Delamination Resistance of CFRP by Stitching-A Review. Composites Science and Technology, 50, 305-317. https://doi.org/10.1016/0266-3538(94)90019-1 
[5] Göktaş, D., Kennon, W.R. and Potluri, P. (2017) Improvement of Mode I Interlaminar Fracture Toughness of Stitched Glass/Epoxy Composites. Applied Composite Materials, 24, 351-375. https://doi.org/10.1007/s10443-016-9560-X

[6] Fishpool, D.T., Rezai, A., Baker, D., Ogin, S.L. and Smith, P.A. (2013) Interlaminar Toughness Characterisation of 3D Woven Carbon Fibre Composites. Plastics Rubber and Composites, 42, 108-114. https://doi.org/10.1179/1743289812Y.0000000036

[7] Unnikrishnan, K.P. and Thachil, E.T. (2006) Toughening of Epoxy Resins. Designed Monomers \& Polymers, 9, 129-152. https://doi.org/10.1163/156855506776382664

[8] Gorbatikh, L., Lomov, S.V. and Verpoest, I. (2011) Nano-Engineered Composites: A Multiscale Approach for Adding Toughness to Fibre Reinforced Composites. Procedia Engineering, 10, 3252-3258. https://doi.org/10.1016/j.proeng.2011.04.537

[9] Borowski, E., Soliman, E., Kandil, U.F. and Taha, M.R. (2015) Interlaminar Fracture Toughness of CFRP Laminates Incorporating Multi-Walled Carbon Nanotubes. Polymers (Basel), 7, 1020-1045. https://doi.org/10.3390/polym7061020

[10] Godara, A., Mezzo, L., Luizi, F., Warrier, A., Lomov, S.V. and van Vuure, A.W. (2009) Influence of Carbon Nanotube Reinforcement on the Processing and the Mechanical Behaviour of Carbon Fiber/Epoxy Composites. Carbon NY, 47, 2914-2923. https://doi.org/10.1016/j.carbon.2009.06.039

[11] Coleman, J.N., Khan, U., Blau, W.J. and Gun'ko, Y.K. (2006) Small But Strong: A Review of the Mechanical Properties of Carbon Nanotube-Polymer Composites. Carbon NY, 44, 1624-1652. https://doi.org/10.1016/j.carbon.2006.02.038

[12] Karapappas, P., Vavouliotis, A., Tsotra, P., Kostopoulos, V. and Paipetis, A. (2009) Enhanced Fracture Properties of Carbon Reinforced Composites by the Addition of Multi-Wall Carbon Nanotubes. Journal of Composite Materials, 43, 977-985. https://doi.org/10.1177/0021998308097735

[13] Thostenson, E.T., Ren, Z. and Chou, T.W. (2001) Advances in the Science and Technology of Carbon Nanotubes and Their Composites: A Review. Composites Science and Technology, 6, 1899-1912. https://doi.org/10.1016/S0266-3538(01)00094-X

[14] Kostopoulos, V., Baltopoulos, A., Karapappas, P., Vavouliotis, A. and Paipetis, A. (2010) Impact and After-Impact Properties of Carbon Fibre Reinforced Composites Enhanced with Multi-Wall Carbon Nanotubes. Composites Science and Technolo$g y$, 70, 553-563. https://doi.org/10.1016/j.compscitech.2009.11.023

[15] Kostopoulos, V., Karapappas, P., Loutas, T., Vavouliotis, A., Paipetis, A. and Tsotra, P. (2011) Interlaminar Fracture Toughness of Carbon Fibre-Reinforced Polymer Laminates with Nano- and Micro-Fillers. Strain, 47, 269-282.

https://doi.org/10.1111/j.1475-1305.2008.00612.x

[16] Gojny, F.H., Wichmann, M.H.G., Köpke, U., Fiedler, B. and Schulte, K. (2004) Carbon Nanotube-Reinforced Epoxy-Composites: Enhanced Stiffness and Fracture Toughness at Low Nanotube Content. Composites Science and Technology, 64, 2363-2371. https://doi.org/10.1016/j.compscitech.2004.04.002

[17] Davis, D.C. and Whelan, B.D. (2011) An Experimental Study of Interlaminar Shear Fracture Toughness of a Nanotube Reinforced Composite. Composites Part B: Engineering, 42, 105-116. https://doi.org/10.1016/j.compositesb.2010.06.001

[18] Zhou, Y., Pervin, F., Lewis, L. and Jeelani, S. (2008) Fabrication and Characterization of Carbon/Epoxy Composites Mixed with Multi-Walled Carbon Nanotubes. Materials Science and Engineering: A, 475, 157-165.

https://doi.org/10.1016/j.msea.2007.04.043 
[19] Fan, Z., Santare, M.H. and Advani, S.G. (2008) Interlaminar Shear Strength of Glass Fiber Reinforced Epoxy Composites Enhanced with Multi-Walled Carbon Nanotubes. Composites Part A: Applied Science and Manufacturing, 39, 540-554. https://doi.org/10.1016/j.compositesa.2007.11.013

[20] Qiu, J., Zhang, C., Wang, B. and Liang, R. (2007) Carbon Nanotube Integrated Multifunctional Multiscale Composites. Nanotechnology, 18, Article ID: 275708. https://doi.org/10.1088/0957-4484/18/27/275708

[21] Tugrul, S.A., Tanoglu, M. and Schulte, K. (2008) Mode I and Mode II Fracture Toughness of E-Glass Non-Crimp Fabric/Carbon Nanotube (CNT) Modified Polymer Based Composites. Engineering Fracture Mechanics, 75, 5151-5162. https://doi.org/10.1016/j.engfracmech.2008.08.003

[22] Sadeghian, R., Gangireddy, S., Minaie, B. and Hsiao, K.T. (2006) Manufacturing Carbon Nanofibers Toughened Polyester/Glass Fiber Composites Using Vacuum Assisted Resin Transfer Molding for Enhancing the Mode-I Delamination Resistance. Composites Part A: Applied Science and Manufacturing, 37, 1787-1795. https://doi.org/10.1016/j.compositesa.2005.09.010

[23] Kim, K.J., Yu, W.R., Youk, J.H. and Lee, J. (2012) Factors Governing the Growth Mode of Carbon Nanotubes on Carbon-Based Substrates. Physical Chemistry Chemical Physics, 14, 140-141. https://doi.org/10.1039/c2cp42566a

[24] He, X., Zhang, F., Wang, R. and Liu, W. (2007) Preparation of a Carbon Nanotube/Carbon Fiber Multi-Scale Reinforcement by Grafting Multi-Walled Carbon Nanotubes onto the Fibers. Carbon NY, 45, 2559-2563.

https://doi.org/10.1016/j.carbon.2007.08.018

[25] Karapappas, P., Tsantzalis, S., et al. (2008) Multi-Wall Carbon Nanotubes Chemically Grafted and Physically Adsorpted on Reinforcing Carbon Fibres. Advanced Composites Letters, 17, 103-107. https://doi.org/10.1177/096369350801700304

[26] An, Q., Rider, A.N. and Thostenson, E.T. (2012) Electrophoretic Deposition of Carbon Nanotubes onto Carbon-Fiber Fabric for Production of Carbon/Epoxy Composites with Improved Mechanical Properties. Carbon NY, 50, 4130-4143. https://doi.org/10.1016/j.carbon.2012.04.061

[27] De Greef, N., Zhang, L., Magrez, A., Forró, L., Locquet, J.P. and Verpoest, I. (2015) Direct Growth of Carbon Nanotubes on Carbon Fibers: Effect of the CVD Parameters on the Degradation of Mechanical Properties of Carbon Fibers. Diamond and Related Materials, 1, 39-48. https://doi.org/10.1016/j.diamond.2014.11.002

[28] Zhang, J., Li, W., Soga, T., Jimbo, T. and Tanji, T. (2012) Synthesis of High-Density Vertically Aligned Carbon Nanotubes Using Ultrasonic Nebulizer. Material Science and Applications, 3, 213-217. https://doi.org/10.4236/msa.2012.34031

[29] Zhang, H., Liu, Y., Kuwata, M., Bilotti, E. and Peijs, T. (2015) Improved Fracture Toughness and Integrated Damage Sensing Capability by Spray Coated CNTs on Carbon Fibre Prepreg. Composites Part A: Applied Science and Manufacturing, 70, 102-110. https://doi.org/10.1016/j.compositesa.2014.11.029

[30] Resoltech Resin Resolcoat 1400 Data Sheet. https://www.resoltech.com/en/products/epoxy/1400-detail.html

[31] Pyrofil Carbon Fiber Datasheet. http://mccfc.com/pan-fiber

[32] Nanocyl Sizing Agent Data Sheet. http://www.nanocyl.com/product

[33] ASTM D 5528-01, ASTM Int. Standard Test Method for Mode I Interlaminar Fracture Toughness of Unidirectional Fiber-Reinforced Polymer Matrix Composites. Standard No. ASTM D5528-01. 
[34] ASTM D 7905/D7905M-14, ASTM Int. Standard Test Method for Determination of the Mode II Interlaminar Fracture Toughness of Unidirectional Fiber-Reinforced Polymer Matrix Composites. 